\title{
A TEORIA DE JOHN RAWLS E A JUSTIÇA DAS DECISÕES DO SUPREMO TRIBUNAL FEDERAL NOS PEDIDOS DE MEDICAMENTOS DE ALTO CUSTO
}

\author{
JOHN RAWLS' THEORY AND THE FAIRNESS OF SUPREME FEDERAL COURT \\ DECISIONS IN HIGH-COST DRUG CLAIMS
}

\author{
Cristina Godoy Bernardo de Oliveira ${ }^{1}$ \\ Luis Augusto Teixeira Morais ${ }^{2}$
}

\begin{abstract}
RESUMO
O presente artigo objetiva analisar a justiça das decisões do Supremo Tribunal Federal (STF) sobre pedidos de medicamentos de alto custo com fundamento na teoria da justiça como equidade de John Rawls. Este estudo tem como principal foco os princípios constitucionais da universalidade e da integralidade do direito à saúde, vistos sob a ótica do mínimo existencial e da reserva do possível. No estudo das decisões do STF, buscou-se verificar a existência de análises relativas à equidade e, sobretudo, às consequências trazidas aos menos favorecidos, pessoas que dependem exclusivamente do SUS para obtenção de tratamentos de saúde, por mais básicos que sejam. Empregando os métodos analíticos e sintéticos, conclui-se que as decisões analisadas se distanciam da justiça como equidade proposta por Rawls, pois, em vista da escassez de recursos, não privilegiam o mínimo social, o que causa prejuízos aos menos favorecidos, justamente, o que Rawls tenta evitar com sua teoria.
\end{abstract}

Palavras-chave: Direito à Saúde. Decisão Judicial. John Rawls. STF. Teoria da Justiça.

\begin{abstract}
Based on the Theory of Justice of John Rawls, this article analyses justice regarding the decisions of the Federal Supreme Court of Brazil (STF) related to public concessions of expensive medicines. This study focuses on constitutional principles like the universality and

\footnotetext{
${ }^{1}$ Doutora em Filosofia do Direito pela Faculdade de Direito da Universidade de São Paulo (2011). Professora Doutora da Faculdade de Direito da Universidade de São Paulo - Campus Ribeirão Preto desde 2011. PósDoutorado em Filosofia do Direito pela Université Paris I - Panthéon/Sorbonne (Agosto/2014 - Dezembro/2015) com vínculo ao Instituto NoSoPhi. Academic Visitor da Faculty of Law - Oxford University onde está desenvolvendo o projeto de pesquisa concernente à Propriedade Intelectual (2015-2016). Faculdade de Direito de Ribeirão Preto da Universidade de São Paulo. São Paulo. Lattes: http://lattes.cnpq.br/9184220537466009 email: cristinagodoy@usp.br

${ }^{2}$ Mestre em Direito pela Faculdade de Direito de Ribeirão Preto da Universidade de São Paulo (2019). Advogado. Faculdade de Direito de Ribeirão Preto da Universidade de São Paulo. São Paulo. Lattes:http://lattes.cnpq.br/9150996252519049 ORCID: https://orcid.org/0000-0003-0808-5187 e-mail: latmorais@gmail.com
} 
integrality in health care illuminated by the minimum existential and the reserve for contingencies. In the study of the STF decisions, we sought to verify the existence of analyses related to equity and, above all, to the consequences brought to the less favored, people who depend exclusively on SUS to obtain health treatments, no matter how basic they may be. Applying the analytical and synthetic methods, the analyses showed that the decisions are not fair in the same way John Rawls argues that because there is no protection of the minimum existential. Thus, there is a health injury to the poor that could be avoided by the theory of justice of John Rawls.

Keywords: Health Law. Judicial Decisions. John Rawls. Federal Supreme Court. Theory of Justice.

\section{INTRODUÇÃO}

O Direito à saúde e sua disponibilização por parte do Estado, conforme previsto na Constituição Federal de 1988, tem suscitado uma série de debates sobre seus limites jurídicos. Entretanto, os debates que envolvem questões de justiça parecem ficar prejudicados, apesar de a saúde pública ser uma área bastante permeada por tais questões.

Nesse sentido, uma abordagem filosófica, com uma perspectiva político-normativa, pode contribuir para o entendimento mais aprofundado do assunto, principalmente, para saber como ele é tratado no âmbito judicial. Assim, há relevância prática nas formulações filosóficas sobre justiça e saúde.

As reivindicações na área da saúde são demandas de grande importância para a justiça, entre outros motivos, por serem restringidas pela escassez de recursos, e isso tem motivado diversas teorias, notadamente, as utilitaristas e aquelas envolvidas na análise econômica do direito a buscarem argumentos que possam propiciar maior utilidade ou maior eficiência.

Dois argumentos muito utilizados pelas Fazendas Públicas em sua defesa nas ações judiciais de pedidos de prestações sociais pelo Estado, sobretudo naquelas decorrentes do direito à saúde, são o mínimo existencial e a reserva do possível, que visam a limitar as prestações estatais aos direitos fundamentais mais básicos e à sua capacidade econômicofinanceira e orçamentária.

A escolha utilitarista desses argumentos é perceptível, dado que há a opção de se aumentar a "felicidade" de um número maior de indivíduos, mesmo que em detrimento da saúde de outros tantos, o que resultaria em um maior saldo líquido de satisfação, o qual seria 
aumentado ainda mais pelo estabelecimento de freios a um possível crescimento da tributação para bancar maiores gastos públicos.

No mesmo sentido do utilitarismo, para a corrente consequencialista/eficientista, o gasto realizado pelo Estado deve ser eficiente no sentido de abranger a maior quantidade de pessoas, como, por exemplo, no tratamento de saúde que abranja doenças mais prevalentes e de controle relativamente fácil e barato.

Por outro lado, para John Rawls (2016), a escolha utilitarista afasta-se dos argumentos de justiça, e por isso, propõe uma teoria que, prioritariamente, leva em conta a justiça como equidade na distribuição do resultado da cooperação social, bem como dos deveres dela advindos.

Para tanto, é necessário que haja igualdade no gozo das liberdades, que as oportunidades sejam equitativamente distribuídas e que os mais favorecidos somente sejam beneficiados por uma distribuição desigual que os privilegie, se este benefício puder elevar as expectativas dos menos favorecidos.

É bastante difícil afirmar a prioridade da igualdade no gozo das liberdades fundamentais, como faz Rawls (2016) em Uma teoria da justiça, quando as condições materiais mínimas não são atendidas. Assim, é claro que as liberdades fundamentais não podem ser exercidas na ausência de um mínimo de garantias materiais aos cidadãos.

Nessa perspectiva, Rawls em $O$ Liberalismo Político, assevera que poderia haver um princípio anterior ao princípio da igualdade ${ }^{3}$, que tivesse por objetivo prover os cidadãos de um mínimo social (RAWLS, 2011).

O mínimo social, que é considerado o núcleo mais fundamental dos bens primários, deve ter sua distribuição regida pelo princípio da igualdade ${ }^{4}$, ou seja, ele deve ser distribuído a todos de maneira igual, pois deve ser composto por uma quantidade e uma diversidade de bens que garantam a existência digna a todos. Somente a partir desse patamar mínimo é que as diferenças poderiam começar a ocorrer, mas ainda assim, respeitadas as limitações do princípio

\footnotetext{
${ }^{3}$ Rawls (2016) sustenta que as pessoas na posição original, limitadas pelo véu da ignorância e por uma lista de princípios selecionados pelas condições formais, escolheriam dois princípios: i) igual direito ao mais extenso sistema de liberdades básicas que seja compatível com um sistema de liberdades idêntico para todos; ii) distribuição das desigualdades econômicas e sociais de forma que simultaneamente: a) propicie o máximo benefício esperado aos menos favorecidos; e b) esteja vinculada a cargos e posições abertos a todos em condições de igualdade equitativa de oportunidades.

${ }^{4}$ A princípio Rawls estabelece o princípio da igualdade apenas com vistas à distribuição das liberdades básicas (liberdades civis, políticas, entre outras), entretanto em formulações posteriores o autor passa a defender que para possibilitar o igual gozo dessas liberdades as pessoas devem ter condições materiais mínimas - o mínimo social.
} 
da diferença no que diz respeito às desigualdades terem de propiciar a elevação das expectativas dos menos favorecidos.

A Constituição Federal de 1988 concedeu alguns direitos sociais fundamentais como o direito à saúde, previsto como um direito universal, isto é, direito de todos os cidadãos, independentemente, de sua posição social e econômica. Pode-se compreender que a universalidade está em consonância com o princípio da igualdade na distribuição do mínimo social em saúde, permitindo acesso universal a bens que têm a importante função de garantir o exercício e o gozo das liberdades fundamentais.

No entanto, outro princípio do direito à saúde é a integralidade, que suscita sérios questionamentos como, até que ponto o Estado está obrigado a fornecer tratamentos de saúde? O conceito de integralidade é coerente com um mínimo social que permite o exercício das liberdades fundamentais e a vida digna? Em outras palavras, qual o mínimo tratamento de saúde garante o gozo e o exercício pleno das liberdades fundamentais e a dignidade da pessoa humana?

Entende-se que um dos grandes desafios da justiça é saber a quantidade e a diversidade de bens primários que compõem o mínimo social, e, especificamente, neste trabalho, no âmbito da saúde. Ou seja, descobrir quantos e quais tratamentos compõem o mínimo social em saúde deve ser uma das questões a serem respondidas, se isso for possível.

Para parte da literatura, a interpretação constitucional que defende a integral atenção à saúde do cidadão tem gerado uma enorme quantidade de processos relativos a pedidos de tratamento, incluindo medicamentos e tratamentos específicos não fornecidos pelo SUS (Sistema Único de Saúde), como aqueles não fabricados no Brasil, não comprovados cientificamente, não comercializados ou não registrados nos órgãos reguladores, como a Anvisa - Agência Nacional de Vigilância Sanitária (TORRES, 2001; LOPES, 2006; SARLET; FIGUEIREDO, 2007; WEICHERT, 2010; LIMA, 2013; LIMA, 2016).

Os tratamentos médicos que estão fora das políticas estabelecidas pelo SUS, quando garantidos pelos juízos de todo o país, conforme autores como Scaff (2013), Wang (2013), Lopes (2013), entre outros, criam desequilíbrios orçamentários a Municípios e Estados, que alegam, na maioria das defesas, que há uma reserva do possível que limita a oferta de tratamentos e que o mínimo existencial foi ultrapassado.

Assim, diferentes interpretações da Constituição surgem na tentativa de limitar ou expandir o pacote de serviços em saúde disponibilizado aos cidadãos. Porém, para Castro 
(2012), uma vez identificado o mínimo existencial em saúde, esse direito deve ser satisfeito, não se admitindo qualquer restrição posterior, já que essa é uma exigência do ordenamento jurídico, segundo o princípio do não retrocesso social.

Em vista dessa situação, o presente artigo objetiva, a partir da teoria da justiça como equidade de Rawls (2016), verificar: i) se o mínimo existencial e a reserva do possível estão presentes nesta teoria e como se apresentam; ii) o que são a universalidade e a integralidade garantidas pela Constituição Federal de 1988, como são abrangidas nas políticas do SUS e se elas se adéquam ao conceito de mínimo social rawlsiano; iii) o papel do judiciário nas questões relativas ao direito à saúde; iv) a capacidade da teoria da justiça como equidade de John Rawls balizar a decisão judicial em saúde; v) o emprego e a delimitação pelo STF dos conceitos-chave: mínimo existencial, reserva do possível, universalidade e integralidade; e, a partir disso: vi) analisar se a adjudicação ou não de tratamentos de saúde pelo Supremo Tribunal Federal é justa, na medida em que argumentos e motivações presentes nas decisões se enquadram aos princípios de justiça de John Rawls.

Para atender a esses objetivos utilizou-se de um estudo teórico-filosófico e normativo, por meio de análises e diálogos entre John Rawls e seus principais comentaristas e críticos. Utilizou-se da mesma técnica analítica e dialógica na leitura dos autores que tratam dos conceitos-chave elencados nos pontos de verificação e daqueles que estudam a temática da saúde pública na Constituição Federal de 1988, tanto sob a perspectiva doutrinária como jurisprudencial.

Após a depuração dos principais relevos da teoria da justiça sob análise e dos principais conceitos chegou-se a conclusões e sínteses que foram posteriormente utilizadas para balizarem a análise qualitativa das decisões do STF, selecionadas de acordo com o método descrito no item "Decisões analisadas: impactos financeiros gerados e informações sobre a incorporação pela CONITEC".

Essas conclusões e sínteses serviram como uma lente específica para ampliar a visão sobre como o STF emprega e delimita os conceitos-chave, trazer à tona os principais argumentos ou motivações de justiça utilizados em suas decisões e, por fim, verificar se esses argumentos ou motivações se enquadram na teoria da justiça rawlsiana, tendo em vista o princípio da equidade que se vislumbra no cuidado em não trazer prejuízos aos menos favorecidos. 


\section{O MÍNIMO EXISTENCIAL, A RESERVA DO POSSÍVEL E A TEORIA DA JUSTIÇA COMO EQUIDADE}

De modo geral, o mínimo existencial é entendido como o conjunto de condições materiais mínimas que garante uma vida digna, que propicia o gozo e a fruição dos direitos individuais e políticos. Por outro lado, a reserva do possível é entendida como a insuficiência de recursos financeiros por parte do Estado para atender a todas as demandas sociais, e de modo menos frequente, como a impossibilidade técnica, por exemplo, quando se pretende distribuir de maneira geral e gratuita um medicamento em fase experimental. A origem de ambos os conceitos remonta aos debates sobre direitos sociais ocorridos na Corte Constitucional alemã, na década de 1950.

O mínimo existencial deve ser entendido como um limite imposto pela racionalidade econômica à efetivação dos direitos sociais, racionalidade que passa a reduzido-los à sua essencialidade. Por isso, pode-se afirmar que o mínimo existencial estipulado pelas políticas públicas, com base nos parâmetros constitucionais, é definido pela reserva do possível (limitações orçamentárias, técnicas etc.) e não pode ser, novamente, no âmbito judicial, limitado ou restringido pelo mesmo argumento (reserva do possível).

Em sua teoria da justiça como equidade, Rawls (2016) objetiva formular uma concepção de justiça social, a partir da escolha consensual dos princípios de justiça realizada em um acordo original que passará a ser um padrão para a avaliação dos aspectos distributivos da estrutura básica da sociedade.

O autor supõe que as partes do acordo original possuem interesses por bens sociais primários, coisas que se presume que todos os seres humanos queiram racionalmente. Nesta lista de bens primários, há uma parte essencial, representada pelas necessidades básicas, denominada de mínimo social. Assim, alimentação, habitação, educação e saúde constituem o mínimo social. Os demais bens primários que o ultrapassam são necessários à realização dos planos de vida de cada indivíduo de acordo com sua concepção pessoal de bem (RAWLS, 2016).

O mínimo social é fundamental para que as pessoas possam fruir os iguais direitos fundamentais e liberdades, pois oferece condições materiais e sociais mínimas para uma existência digna e, ainda, possibilita a concorrência às iguais oportunidades de maneira 
equitativa, sendo, por conseguinte, distribuído conforme o princípio da igualdade. Desse modo, somente após este ponto de igualdade mínima, é que deve ser aplicado o princípio da diferença.

Pode-se afirmar que o mínimo existencial e a reserva do possível estão presentes na teoria da justiça como equidade de Rawls e que ambos servem à manutenção da cooperação social.

O mínimo existencial pode ser equiparado ao mínimo social, que é regido pelo princípio da igualdade, já que não garanti-lo a todos seria injusto, pois assim como as liberdades não devem ser distribuídas de maneira desigual, nem com vistas a uma melhoria na distribuição da riqueza, o mínimo social não deve ser distribuído de maneira desigual, nem se objetivar melhorar a condição dos menos favorecidos. Ou seja, o mínimo social garante a igualdade de gozo das liberdades.

Em relação à reserva do possível esta não é tão evidente na teoria da justiça como equidade, mas pode ser depreendida como um princípio que visa a impedir o exagero na tributação, através de um limite do gasto público à possibilidade orçamentária, econômica e financeira. Como se verá adiante, na posição original os cidadãos, cobertos pelo véu da ignorância, não sabem nada sobre sua própria condição de vida: se mais pobres e muito dependentes da distribuição do mínimo social ou se os principais mantenedores do sistema de distribuição, o que é essencial para uma escolha não-egoística.

A obra de Rawls pode ser entendida como necessária para dar suporte teóricofilosófico à minimização dos direitos sociais, que passaram a ser considerados excessivos após as diversas crises do capitalismo. Dessa forma, os conceitos de mínimo social e do não exagero na tributação se contextualizam com a racionalização da distribuição dos direitos sociais, que passaram a ser considerados apenas aqueles fundamentais a uma vida digna, entre outros, no sentido de possibilidade do gozo das iguais liberdades.

A teoria da justiça proposta por Rawls é uma tentativa de suplantar o utilitarismo, que, para o autor, proporciona bases frágeis às instituições democráticas, já que o maior bem-estar social não deveria se basear em sacrifícios individuais.

Entretanto, Rawls não conseguiu, como desejava, se afastar tanto do utilitarismo, uma vez que, como chega a afirmar, há outros consensos que podem superar os planos individuais, como o bem-estar social, que não pode ser entendido de outra forma, senão como o maior bem comum, que depende da distribuição em benefício de uns e em prejuízo de outros e exige critérios distributivos centrados na equidade. 


\section{A TEORIA DA JUSTIÇA COMO EQUIDADE COMO GUIA PARA A DECISÃO JUDICIAL}

Não é de se estranhar que argumentos utilitaristas, como o mínimo existencial e a reserva do possível estejam presentes na teoria da justiça como equidade de Rawls. No entanto, o utilitarismo rawlsiano é mitigado pela importância que ele confere à proteção dos menos favorecidos e pelo estabelecimento de um mínimo social igual para todos, sendo que o autor não consegue elaborar uma teoria plenamente contrária ao utilitarismo, mas consegue mitigálo com o uso da equidade da distribuição, importante para qualquer tipo de decisão envolvendo questões de justiça.

Dessa maneira, defende-se que a teoria da justiça como equidade de Rawls, apesar de voltada aos aspectos da política normativa, também pode ser utilizada como um guia para a decisão judicial, pois possui importantes diretrizes morais - os princípios de justiça.

A teoria da justiça como equidade altera a lógica da estrutura normativa proposta por Hans Kelsen, oferecendo outro sentido à "norma hipotética fundamental", que passa a ser entendida como o conjunto dos princípios de justiça escolhidos na posição original, que deve nortear a Constituição, as leis e normas em geral, assim como a decisão judicial, descaracterizando o purismo jurídico da ciência do direito, o que é congruente com o neoconstitucionalismo e o pós-positivismo.

Dessa maneira, a justiça da Constituição ou de qualquer dispositivo constitucional, lei ou mesmo decisão judicial pode ser verificada por meio da simulação mental das deliberações feitas na posição original, pois como afirma Rawls (2011, p. 31-32) "podemos [..] entrar nessa posição a qualquer momento simplesmente argumentando a favor de princípios de justiça em consonância com as restrições à informação que foram especificadas" (véu de ignorância). O importante é que se analise a justiça da norma legal ou judicial, de acordo com os dois princípios de justiça, por meio da escolha das alternativas "menos piores dentre as piores" (princípio que também se liga à reserva do possível e ao mínimo existencial).

Nesse sentido, concorda-se com um dos mais famosos críticos de Rawls, Michael Sandel (2005), que a escolha dos princípios de justiça não é propriamente um acordo interpartes, mas uma espécie de cognitivismo, no qual é possível encontrar os princípios de justiça por meio da razão.

Diante do exposto, o objetivo de analisar decisões judiciais e verificar sua aderência aos princípios de justiça escolhidos na posição original torna-se possível, escolha que é 
entendida como um exercício de reflexão autônomo, sendo que aquele que faz a análise do atendimento aos princípios de justiça há de se colocar no lugar dos menos favorecidos.

\section{A UNIVERSALIDADE E A INTEGRALIDADE DO DIREITO À SAÚDE NA CONSTITUIÇÃO FEDERAL DE 1988}

A partir da Constituição Federal de 1988, o direito à saúde passou a ser previsto como um direito regido pelos princípios da universalidade e da integralidade, congruente com os critérios estabelecidos na Reforma Sanitária, ocorrida nos anos 80, que foi uma espécie de guia para a constitucionalização do direito à saúde no país.

A universalidade é interpretada de maneira diversa pela doutrina. Uma corrente dominante a entende como o acesso de qualquer cidadão, independentemente, de sua condição socioeconômica, aos serviços de saúde patrocinados pelo Estado de forma gratuita (literalidade da norma constitucional, interpretação da qual se compartilha) (SLAIBI, 2004; COHN, 2005; BOTAZZO, 2008). Uma segunda corrente defende que a universalidade deve ser restrita à capacidade do Estado em fornecer de modo igual e simultâneo a todos os cidadãos os mesmos serviços de saúde gratuitos, e para isso, estes devem ser os mais básicos e menos custosos (LOPES, 2006; LEAL, 2008). Outros autores, ainda, entendem que o acesso não deve ser universal, mas direcionado apenas aos mais pobres (TORRES, 2001; LIMA FILHO, 2006; SARLET; FIGUEIREDO, 2007), o que contraria a vontade constitucional e a sua clareza semântica.

Quanto à integralidade, também há muitas discordâncias em relação à sua interpretação, que varia desde o movimento da medicina integral e sua crítica aos currículos formadores de médicos com atitudes fragmentárias e reducionistas, passando pela forma de organização dos serviços e das práticas de saúde, em que se discute a tentativa de superar a dissociação entre saúde pública e assistencial (filantropia) e, por outro lado, entre saúde individual e saúde coletiva, até a interpretação que defende o fim da dicotomia existente entre ações preventivas e curativas (BRITO-SILVA et al, 2012).

No entanto, para parte da doutrina, dentre os quais Pinheiro (2007) e Aith (2010), a integralidade se refere ao acesso ao mais complexo, inovador e custoso tratamento, a despeito das consequências advindas, como o exaurimento de recursos públicos por poucos indivíduos, o que leva a situações de injustiça. 
Nesse contexto, poder-se-ia imaginar, que qualquer demanda de saúde não constante das políticas do SUS, deveria, obrigatoriamente, ser atendida a partir de pedidos ao Poder Judiciário. No entanto, há a necessidade de que existam critérios objetivos que possam assegurar o acesso dos cidadãos aos tratamentos cuja eficácia científica esteja comprovada, dentre outros pré-requisitos, aqueles que possibilitem ao Estado custeá-los de maneira segura e visando a boa aplicação dos recursos públicos, principalmente, no atendimento aos menos favorecidos.

Porém, para se chegar a esses critérios objetivos, a universalidade e a integralidade devem ser interpretadas a partir dos princípios do mínimo existencial/social e da reserva do possível, haja vista que qualquer interpretação que não leve em conta esses limites pode ser contrária à justiça na distribuição equânime do direito à saúde.

\section{A UNIVERSALIDADE E A INTEGRALIDADE FRENTE AO MÍNIMO SOCIAL E À RESERVA DO POSSÍVEL}

Há também grandes divergências na interpretação do mínimo existencial/social em saúde e se este mínimo pode ser restringido pela reserva do possível, em vista dos princípios da integralidade e da universalidade, sendo que autores como Torres (2003), Sarlet e Figueiredo (2007), entre outros, defendem apenas a saúde coletiva e as emergências médicas como o mínimo existencial. Outros, como Barcellos (2013), defendem que o mínimo existencial se refere, além da saúde coletiva, ao nível básico de atendimento à saúde individual.

A contrario sensu, defende-se que o mínimo existencial/social em saúde, necessário para garantir o igual gozo e o exercício pleno das liberdades fundamentais, como definido por Rawls, corresponde à integralidade e à universalidade, que são representadas pelas Políticas Públicas de abrangência universal do SUS, tanto preventivas quanto curativas, nos três níveis de complexidade da atenção: básica, média e alta complexidade, assim como o fornecimento dos medicamentos e tratamentos já incorporados, conforme a Relação Nacional de Medicamentos Essenciais (RENAME), as listas de medicamentos excepcionais e os Protocolos Clínicos e Diretrizes Terapêuticas do SUS, sendo que a reserva do possível não pode limitar o oferecimento desses serviços ao cidadão, que deve contar com previsão orçamentária suficiente ao seu atendimento, pois se caracteriza como um mínimo estabelecido constitucionalmente e de modo técnico-científico, e, por isso, faz parte dos objetivos precípuos do Estado, que deve 
direcionar recursos suficientes para garanti-lo, em vista da manutenção da cooperação social, e que é definido, preferencialmente, no âmbito das políticas públicas.

Assim, uma vez incorporada determinada prestação terapêutica pelo órgão responsável pelas análises técnico-científicas (Comissão Nacional de Incorporação de Tecnologias do SUS - CONITEC ${ }^{5}$ ), inclusive por meio de procedimentos de consulta pública nacional, esta passa a fazer parte do mínimo existencial/social, ainda que possa haver alguns problemas éticos, já que, em grande parte dos casos, quem provoca o órgão público a incorporar determinado medicamento é a própria indústria farmacêutica que o produz, visto que de outra forma, teria dificuldades intransponíveis à sua comercialização, devido ao elevadíssimo custo de seus produtos, inacessíveis, até mesmo, às pessoas pertencentes às classes mais privilegiadas da população. Porém, mesmo em vista de tais problemas éticos, os critérios técnico-científicos funcionam para mitigar possíveis desvios.

\section{O DIREITO CONSTITUCIONAL À SAÚDE EM FACE DA TEORIA DE RAWLS}

O direito à saúde, previsto na Constituição Federal de 1988, deve ser distribuído de modo igual (universalidade), isto é, sem levar em conta a necessidade econômica de cada indivíduo ou sua posição social, o que se compatibiliza com a aplicação do princípio da igualdade na distribuição do mínimo social prevista por Rawls (2016).

Pode-se pensar que, na posição original as partes do acordo, como desconhecedoras de sua capacidade de custear com recursos próprios os tratamentos de saúde que pudessem vir a precisar, racionalmente, optariam por um sistema universal de saúde que as incluísse, independentemente, da condição financeira que viessem a ter. Nessas condições, poder-se-ia imaginar que as partes escolheriam ter acesso a todo e qualquer conjunto de tratamentos disponíveis, pois poderiam pensar que se necessitassem, deveriam ser atendidas integralmente.

Entretanto, Rawls (2016) afirma que na posição original as partes partilham condições pouco exigentes, ou seja, demandariam tratamentos de saúde fornecidos pelo Estado e exigiriam

\footnotetext{
${ }^{5}$ A Comissão Nacional de Incorporação de Tecnologias no SUS (CONITEC), criada pela Lei nº 12.401, de 28 de abril de 2011, que dispõe sobre a assistência terapêutica e a incorporação de tecnologia em saúde no âmbito do Sistema Único de Saúde (SUS), é um órgão colegiado de caráter permanente, integrante da estrutura regimental do Ministério da Saúde, tem por objetivo assessorar o Ministério nas atribuições relativas à incorporação, exclusão ou alteração pelo SUS de tecnologias em saúde, bem como na constituição ou alteração de protocolos clínicos e diretrizes terapêuticas (BRASIL et al, 2019, p. 5).
} 
um nível de tratamento abrangente, mas que se utilizasse de tecnologia acessível e com eficiência e eficácia comprovadas. Pode-se pensar até mesmo que escolheriam tratamento para todas as condições de saúde, mas cuja técnica/tecnologia possuísse uma relação custo-benefício aceitável, tendo em vista a proteção do próprio mínimo social e o não exagero da tributação, que servem à proteção da cooperação social, pois o véu da ignorância os faz desconhecedores de sua própria posição econômica e social, isto é, não saberiam se seriam preponderantemente os financiadores ou dependentes do sistema de saúde.

Essa característica das partes na posição original faria com que os tratamentos cuja eficácia não fosse comprovada ou com problemas de custo-efetividade fossem rejeitados, o que é compatível com os critérios estabelecidos pela CONITEC para a incorporação de novas tecnologias médicas.

Como a própria política do SUS vai além da assistência básica e compreende os graus de média e alta complexidade, bem como o fornecimento de medicamentos de alto custo incorporados de acordo com critérios técnico-científicos, pode-se admiti-los como o mínimo existencial/social em saúde no Brasil, sendo que aquele tratamento que não estiver presente nos protocolos e listas de medicamentos deve passar por estudos técnicos de incorporação.

Por exemplo, uma pessoa que não obteve sucesso com os tratamentos mais modernos e caros presentes nas listas SUS e distribuídos gratuitamente, vai ao Judiciário requerer uma nova droga, ainda não incorporada ao SUS e de custo elevado. Nesse caso, o juiz somente deve adjudicar tal medicamento se essa decisão não trouxer prejuízos à igual distribuição do mínimo social. Entretanto, essa condição não será atendida, pois uma parte do orçamento dos SUS será realocada para o cumprimento da determinação judicial e vulnerará, inevitavelmente, o mínimo existencial/social.

Em outras palavras, como os recursos orçamentários do SUS estão previstos apenas para a manutenção do mínimo existencial/social, a realocação desses recursos para o atendimento de pedidos que extrapolem mínimo previsto contribui para piorar as condições dos menos favorecidos, pois passam a ser privados desse mínimo. Em vista da piora das condições dos menos favorecidos, que são aqueles que dependem, exclusivamente, do SUS para obter tratamentos de saúde, por mais básicos que sejam, a adjudicação de tratamentos que não estejam previstos nas políticas do SUS é injusta do ponto de vista da teoria da equidade de John Rawls.

No entanto, apenas como exercício argumentativo, suponha-se que a distribuição de remédios de alto custo pelo Poder Judiciário e que não constam das listagens oficiais do SUS 
seja financiada sem prejuízo do mínimo existencial por um orçamento previamente alocado especialmente para essa finalidade, questiona-se: tal distribuição poderia trazer elevação das expectativas dos menos favorecidos (critério rawlsiano de distribuição regida pelo princípio da diferença)? Essa adjudicação seria justa?

Caso se pense apenas em pura e simples elevação das expectativas dos menos favorecidos ou em expectativas desproporcionais, pode-se imaginar que, por exemplo, poderia haver o barateamento dos medicamentos, pois se o Poder Público, único a conseguir custear tratamentos de alto custo, salvo raríssimas exceções, conseguisse ao longo do tempo fazer com que os retornos da indústria farmacêutica se realizassem, tais medicamentos, dentre outros, poderiam ser barateados e abrangeriam mais pessoas.

Por outro lado, a indústria poderia ter estímulo de continuar a investir em pesquisas de novas drogas, o que faria, possivelmente, com que ela expandisse suas operações, gerar empregos e pagar mais impostos (talvez não no Brasil). Dessa forma a elevação das expectativas dos menos favorecidos estaria atendida, porém, e quanto à justiça da distribuição?

Pode-se imaginar que atribuir um orçamento específico à distribuição pelo Judiciário de medicamentos de alto custo e não incorporados às políticas do SUS possa ser uma solução justa, na medida em que mantém o mínimo social de forma íntegra. Entretanto, o orçamento destinado à saúde deve ser estipulado de modo universal e global, sendo que qualquer valor destinado à saúde deve ser direcionado ao atendimento de todos e de modo igualitário, o que não ocorreria nesse caso, principalmente, porque a maioria das ações que servem à adjudicação de tratamentos de alto custo é manejada individualmente e muitas pessoas nem ao menos sabem que podem ou conseguem acessar o Judiciário para conseguir medicações inovadoras ou nem mesmo têm acesso a médicos tão atualizados em suas prescrições.

Assim, em vista de uma mera expectativa de melhora dos menos favorecidos frente a uma real diminuição de suas perspectivas, dado o comprometimento orçamentário gerado por uma alocação excludente, que privilegiará a poucos, e o não atendimento ao princípio da universalidade em saúde, depreende-se que a adjudicação de medicamentos de alto custo não previstos nas políticas do SUS gera impacto negativo muito maior do que qualquer argumento de expectativa de melhoria dos menos favorecidos. 


\section{A JUDICIALIZAÇÃO DOS DIREITOS SOCIAIS FUNDAMENTAIS - O DIREITO À SAÚDE}

A sindicabilidade ou a possibilidade de judicialização dos direitos sociais fundamentais possui correntes específicas e contrapostas que podem ser encontradas tanto no âmbito normativo como no âmbito político.

No âmbito normativo, a divisão se dá entre as correntes que defendem a possibilidade ou não de o Poder Judiciário aplicar as normas constitucionais sobre direitos fundamentais, de maneira direta, isto é, anteriormente à existência de leis infraconstitucionais, de acordo com as características da própria norma (ACCA, 2009).

No âmbito político, a divisão se dá entre as correntes que defendem ou não a legitimidade do Poder Judiciário para intervir nas decisões políticas e qual o grau de intervenção permitido (ACCA, 2009).

No âmbito normativo, a teoria da norma constitucional de Alexy (2007) é preponderante: a norma será vinculante quando sua vulneração puder ser declarada por um Tribunal Constitucional, referindo-se a um mínimo existencial, e não será vinculante quando tiver enunciado programático, isto é, quando expuser pretensões prestacionais de direitos fundamentais em normas imperfeitas ${ }^{6}$.

Em relação ao âmbito político, a discussão sobre a possibilidade de intervenção do Poder Judiciário nos direitos sociais fundamentais divide-se entre aqueles que i) admitem o controle judicial apenas quanto aos aspectos procedimentais das Políticas Públicas - corrente procedimentalista $^{7}$; ou ii) admitem o controle judicial pleno, tanto em relação ao aspecto procedimental quanto ao aspecto material das Políticas Públicas - corrente substancialista ${ }^{8}$.

Apesar de se aceitar a aplicabilidade imediata da norma constitucional sobre os direitos sociais fundamentais e o controle judicial pleno das Políticas Públicas, as particularidades

\footnotetext{
${ }^{6}$ No mesmo sentido, Canotilho (2008) afirma que, no campo das prestações existenciais mínimas do direito à vida, o cidadão tem um direito subjetivo originário e definitivo a estas prestações, ao qual corresponde um dever correlativo por parte do Estado, isto é, uma posição jurídico-prestacional que é garantida por normas vinculantes reconhecedoras de direitos subjetivos definitivos a prestações.

7 De acordo com Martins (2015) a corrente procedimentalista, encabeçada por Habermas, entende que a Constituição não pode ser vista como uma ordem jurídica global e suprapositiva de valores. Consequentemente, os direitos fundamentais dependem da implementação das respectivas Políticas Públicas, sendo vedada a fruição individual advinda da decisão judicial, posto que ofenderia o procedimento democrático.

${ }^{8}$ A corrente substancialista, liderada por Cappelletti, defende o caráter principiológico e dirigente da Constituição, sendo que as normas que definem os direitos e as garantias fundamentais possuem aplicação imediata e são plenamente capazes de ser sindicadas perante o Judiciário, que pode adjudicá-los individualmente (MARTINS, 2015).
} 
envolvidas no direito à saúde levam à necessidade de que os tratamentos disponibilizados pelo Estado sejam definidos de acordo com critérios técnico-científicos, o que acaba por limitar a acurácia da avaliação pelo Judiciário sobre terapêutica solicitada e ainda não incorporada às políticas do SUS, a despeito de qualquer tipo de assistência técnica, já que a decisão judicial não é apropriada à adjudicação de novas tecnologias de saúde, sendo que as limitações nesta área não se dão apenas no âmbito normativo ou político, mas, sobretudo, devido à necessidade de decisões balizadas por uma metodologia científica, que são tomadas pela CONITEC.

Desse modo, concorda-se com Sarlet e Figueiredo (2007) sobre a limitação técnica da decisão judicial, que também deve ser compreendida na reserva do possível e que limita a adjudicação do tratamento ainda não considerado como componente do mínimo existencial, que é tarefa do SUS e de seus órgãos técnicos, pois a análise da razoabilidade e da adequação de uma determinada prestação terapêutica, bem como sua essencialidade é muito mais abalizada quando realizada por meio de metodologias técnico-científicas referendadas internacionalmente, do que quando realizada por um juiz ou por um colegiado de magistrados, a despeito de todas as provas de necessidade. A análise da eficácia/eficiência do tratamento solicitado é mais qualificada no âmbito da CONITEC, devido, principalmente, à maior participação pública (consulta pública) e na abrangência da decisão, que vai muito além da adjudicação individual e torna-se acessível a todos os que necessitam.

Poder-se-ia questionar que, se não há tratamento previsto para determinada doença no SUS, mesmo com importante representação epidemiológica e baixo custo, o judiciário poderia adjudicar este tratamento, desconsiderando a necessidade de estudos técnicos a serem realizados pela área de incorporação de novas terapêuticas, ou ainda que as ações coletivas possuem o mesmo potencial de abranger a todos aqueles que se enquadrem na espécie, de modo semelhante às políticas públicas.

Contudo, mesmo manejada por ações coletivas, consideradas mais justas do que a adjudicação individual devido às suas características particulares ${ }^{9}$, o déficit procedimental, principalmente em relação aos aspectos técnico-científicos, retira do Poder Judiciário a

\footnotetext{
${ }^{9}$ No âmbito da saúde, as ações coletivas propiciam economia processual, maior acesso à justiça, efetividade do direito material e diminuição das ações individuais. Permitem, ainda, uma discussão mais abrangente das políticas públicas, proporcionando uma ideia mais realista das dimensões da necessidade e da quantidade de recursos disponíveis. Soma-se a isso o fato de que os Tribunais pátrios admitem a legitimidade do Ministério Público na propositura de ação civil pública em defesa da saúde, com produção de efeitos erga omnes, o que privilegia a igualdade e universalidade (THIBAU; GAZZOLA, 2014).
} 
necessária legitimidade para a adjudicação de uma nova terapêutica, independentemente, de seu custo.

Assim, entende-se que o melhor a ser feito pelo Judiciário diante de uma terapêutica ainda não incorporada, cuja eficácia/eficiência e custo-efetividade seja desconhecida, é instar o SUS a iniciar a análise de incorporação em regime de urgência, em virtude, por exemplo, do número de processos sobre o mesmo objeto ou em vista da preponderância da enfermidade.

Em suma, o papel do Judiciário é o de fazer cumprir a política pública, isto é, garantir a distribuição do mínimo social em saúde e de determinar que os estudos de incorporação sejam iniciados, respeitando-se a decisão final da CONITEC, mesmo se esta entender por bem não recomendar a incorporação do medicamento, pois o Judiciário não é competente para análises que demandam critérios científicos específicos, mesmo em vista de possível auxílio técnico.

Diante dos argumentos trazidos, poder-se-ia alegar que a aplicação da teoria da justiça como equidade de Rawls para a análise da decisão sobre adjudicação de medicamentos de alto custo seria inócua, pois, ao cabo, esta é uma decisão que cabe apenas aos órgãos técnicos do executivo. Entretanto, tal alegação não se sustenta, pois a teoria sob análise serve como fundamento ao indeferimento de pedidos de tratamentos não constantes das políticas do SUS, sobretudo, para evitar prejuízos aos menos favorecidos.

Por outro lado, em razão da massiva adjudicação de medicamentos de alto custo não incorporados pelo SUS, verificar a existência ou não de análises e fundamentações, pelo STF, de princípios relativos à equidade e, sobretudo, das consequências aos menos favorecidos, sob a perspectiva do mínimo existencial/social e da reserva do possível, é relevante, haja vista a importância do uso de critérios de justiça distributiva na fundamentação das decisões judiciais e as gravíssimas consequências da não utilização de tais critérios.

\section{DECISÕES ANALISADAS: IMPACTOS FINANCEIROS GERADOS E INFORMAÇÕES SOBRE A INCORPORAÇÃO PELA CONITEC}

A partir de agora passa-se à descrição do método de coleta das decisões analisadas e de suas principais informações.

Dadas as evidentes limitações de tempo, tentou-se responder às questões relativas a como o STF decide no âmbito do direito à saúde, aplicando-se a análise qualitativa a algumas das suas decisões mais importantes em relação a pedidos de medicamento de alto custo, dos 
últimos 5 (cinco) anos, de 24/05/2014 à 24/05/2019, e que possuem em sua discussão os argumentos do mínimo existencial e da reserva do possível ou argumentos que os tangenciem.

Para tanto foram feitas duas pesquisas no portal do Supremo Tribunal Federal, conforme endereço eletrônico http://portal.stf.jus.br/.

Na primeira pesquisa, o campo "pesquisa livre" foi preenchido com o seguinte termo de pesquisa: medicamento e alto custo, no campo "data", foram informadas as datas acima referidas, no campo "legislação" foi selecionada a Constituição Federal de 1988 e informado o artigo 196, e, por fim, foram selecionados todos os tipos de decisão.

A pesquisa retornou 4 (quatro) acórdãos, 103 (cento e três) decisões monocráticas, 15 decisões da presidência e 1 (uma) Repercussão Geral. Importante informar que, novamente, devido à limitação temporal, optou-se por incluir na leitura seletiva apenas as decisões que cumpriram os seguintes critérios: que possuíam no corpo do texto da decisão, uma das seguintes expressões, utilizando-se para isso a ferramenta de pesquisa do "Adobe Acrobat Reader DC®": "mínimo existencial" ou "reserva do possível" ou "orçamento" ou "equidade", sendo que foram incluídos na leitura seletiva 3 acórdãos; 21 decisões monocráticas; 9 decisões da presidência; e uma única decisão que a pesquisa retornou, que trata de repercussão geral do tema "solidariedade dos entes federativos no custeio de tratamentos de saúde", conforme Recurso Extraordinário 855.178 RG/SE, de relatoria do Ministro Luiz Fux, no qual o Tribunal Pleno estabeleceu a tese, em 23 de maio de 2019, de que os entes da federação são solidariamente responsáveis nas demandas prestacionais da área da saúde, em virtude da descentralização e da hierarquização previstas constitucionalmente.

Em uma segunda pesquisa no portal do STF foi preenchido no campo "pesquisa livre" o seguinte termo de pesquisa: medicamento e alto custo e reserva do possível e mínimo existencial, no campo "data", foram informadas as datas anteriormente referidas, no campo "legislação" não foi selecionada nenhuma legislação e, por fim, foram selecionados todos os tipos de decisão.

A pesquisa retornou 11 (onze) decisões monocráticas e 3 (três) decisões da presidência. Nas decisões trazidas, houve repetição de 5 (cinco) decisões monocráticas e de 1 (uma) decisão da presidência presentes na primeira pesquisa.

Desta segunda pesquisa, foram adicionadas para a leitura seletiva 6 (seis) decisões monocráticas e 2 (duas) decisões da presidência, que na verdade se tratavam do mesmo STP 101 ES (Suspensão de Tutela Provisória) sendo que a primeira decisão tratou de negativa da 
medida cautelar de suspensão liminar da tutela provisória e a segunda decisão confirmou a negativa de suspensão.

A posterior leitura seletiva buscou separar as decisões de maior impacto dentre aquelas que discutiram pedidos de medicamentos de alto custo sob a perspectiva da reserva do possível, do mínimo existencial, da equidade, dos limites orçamentário/financeiros ou de temáticas que as tangenciavam.

Foram descartadas as decisões de cunho estritamente processual, nas quais não foram discutidos quaisquer pontos em relação ao mérito, bem como as decisões cujo objeto não foi medicamento de alto custo e aquelas em que não houve discussão em relação ao alto custo, ao mínimo existencial e à reserva do possível, não importando se em sua vertente orçamentáriofinanceira ou relativa à separação de poderes.

Da leitura seletiva, foram escolhidas 10 decisões para análise aprofundada conforme a teoria da justiça como equidade de John Rawls empregando-se os métodos analítico e sintéticos.

Pela relevância das decisões, foram incluídas as seguintes decisões: STP 24 MC/MG - Medida Cautelar na Suspensão de Tutela Provisória, Relator(a): Min. Presidente, Julgamento: 25/04/2018; STA 761/DF - Suspensão de Tutela Antecipada, Relator(a): Min. Presidente, Julgamento: 26/11/2014; e SS 4972/SP - Suspensão de Segurança, Relator(a): Min. Presidente, Julgamento: 10/12/2014, resultando em 13 (treze) decisões para análise aprofundada.

Importante ressaltar, que das 13 decisões estudadas, apenas uma delas se tratou de uma ação civil pública, ou seja, mesmo em se tratando de um tema que a priori atinge a coletividade, o número de ações civis públicas solicitando tratamentos se comparado às ações individuais é muito inferior. Optou-se por elencá-la, pois se trata de uma situação que ilustra como uma ação coletiva tem tratamento diferenciado em relação aos processos individuais, porque dado o impacto de uma decisão que abrange a coletividade, o judiciário passa a ter muito mais cuidado ao medir as consequências econômicas ao decidir sobre tratamentos com custo elevado.

Ressalta-se, também, que o objetivo da pesquisa qualitativa das decisões não foi comparar como o STF decide em cada ação individual elencada, mas explorar os fundamentos nelas presentes e trazê-los à apreciação. Nesse sentido, seria empobrecedor ao trabalho não analisar os fundamentos da ação civil pública e cotejá-los com aqueles presentes nas ações individuais, já que as questões de equidade devem ser levadas em conta tanto nas decisões das ações individuais quanto das ações coletivas. 
As treze decisões analisadas em profundidade foram as seguintes, conforme data de julgamento:

1. Agravo Regimental no Recurso Extraordinário no 818.572 / CE, Relator Min. Dias Toffoli, Primeira Turma, Julgamento: 02/09/2014.

Trata-se de um Agravo Regimental no Recurso Extraordinário interposto pelo Estado do Ceará e pela União contra decisão que denegou seguimento ao recurso extraordinário. O julgamento se deu pela $1^{\text {a }}$ Turma, em 02 de setembro de 2014, por unanimidade e nos termos do voto do Relator Ministro Dias Toffoli, negaram provimento em relação ao Estado do Ceará e entenderam o agravo da União prejudicado.

Os recorrentes desejavam reverter decisão em grau de apelação, proferida pelo TRF da $5^{\text {a }}$ região que manteve sentença de primeiro grau que adjudicou medicamento de alto custo.

O peticionante é portador de Neoplasia de Pulmão e solicitou o medicamento Tarceva $150 \mathrm{mg}$ (cloridrato de erlotinibe), cujo preço ao consumidor presente na listagem atualizada de custo de medicamentos ${ }^{10}$ não foi encontrado e o preço para compras públicas sem incidência de ICMS é R \$ 5.923,33 ao mês. O custo anual é de $\mathrm{R} \$ 71.079,96$ calculado de acordo com o preço de venda ao governo (compras públicas).

A Portaria $n^{\circ} 51$, de 7 de novembro de 2013 tornou pública a decisão de incorporar o cloridrato de erlotinibe para o tratamento do câncer de pulmão de células não pequenas avançado ou metastático, conforme sítio da internet http://conitec.gov.br/images/Relatorios/Portaria/2013/CP38a40-PT51.pdf, acessado em 17/06/2019.

A decisão do STF de confirmar a decisão a quo favorável ao peticionante se deu pouco menos de um ano após sua incorporação pelo SUS.

2. STA 761 / DF - Suspensão de Tutela Antecipada, Relator(a): Min. Presidente Ricardo Lewandowski, Julgamento: 26/11/2014.

Trata-se de pedido de Suspensão de Tutela Antecipada ajuizada pelo Município de São Paulo, objetivando suspender os efeitos da tutela antecipada deferida pelo Tribunal de Justiça do Distrito Federal, para fornecer o medicamento Soliris (Eculizumabe) a portador de Hemoglobinúria paroxística noturna. Pedido de suspensão de antecipação de tutela indeferido pelo Presidente do STF, o Ministro Ricardo Lewandowski, em 26 de novembro de 2014. 
O peticionante é portador de Hemoglobinúria paroxística noturna e solicita o medicamento Soliris (Eculizumabe) $10 \mathrm{mg} / \mathrm{ml}$, cujo preço ao consumidor sem incidência de IMCS é de $\mathrm{R} \$ 17.964,79$ e o preço para compras públicas sem incidência de ICMS é $\mathrm{R} \$$ $14.343,09$. O custo anual de $\mathrm{R} \$ 172.117,08$ foi calculado de acordo com o preço de venda ao governo (compras públicas).

A Portaria $\mathrm{n}^{\circ}$ 77, de 14 de dezembro de 2018 tornou pública a decisão de incorporar o eculizumabe para tratamento de pacientes com hemoglobinúria paroxística noturna (HPN), conforme sítio da internet http://conitec.gov.br/images/Relatorios/Portaria/2018/Portarias SCTIE_75a81_2018.pdf, acessado em 17/06/2019.

A decisão do STF de manter a decisão a quo favorável ao peticionante se deu aproximadamente 4 anos antes de sua incorporação pelo SUS.

3. SS 4972 / SP - Suspensão de Segurança Relator(a): Min. Presidente Ricardo Lewandowski, Julgamento: 10/12/2014

Trata-se de pedido de Suspensão de segurança ajuizada pelo Município de Santo André, objetivando suspender os efeitos da tutela antecipada deferida pelo Tribunal de Justiça do Estado de São Paulo, para fornecer o medicamento Aubagio $14 \mathrm{mg}$ (teriflunomida) a portadora de esclerose múltipla e diabetes. Pedido de suspensão de segurança de indeferido pelo Presidente do STF, o Ministro Ricardo Lewandowiski, em 10 de dezembro de 2014.

O peticionante é portador de esclerose múltipla e solicita o medicamento Aubagio 14 $\mathrm{mg}$ (teriflunomida), cujo preço ao consumidor sem incidência de IMCS é de R \$4.669,41 e o preço para compras públicas sem incidência de ICMS é de $\mathrm{R} \$ 3.728,06$. O custo do tratamento mensal é de $\mathrm{R} \$ 3.728,06$, enquanto o custo anual é de $\mathrm{R} \$ 44.736,72$, calculado de acordo com o preço de venda ao governo (compras públicas.

A Portaria $\mathrm{n}^{\circ}$ 19, de 19 de abril de 2017 tornou pública a decisão de incorporar a teriflunomida para o tratamento da esclerose múltipla remitente recorrente, conforme sítio na internet http://conitec.gov.br/images/Relatorios/Portaria/2017/PortariaSCTIE-17a19_2017.pdf acessado em 17/06/2019.

A decisão do STF de manter a decisão a quo favorável ao peticionante se deu pouco mais de 3 anos antes da recomendação de incorporação pelo SUS.

4. Agravo Regimental na Suspensão de Liminar nº 815 / SP, Relator: Ministro Presidente Ricardo Lewandowski, Julgamento: 07/05/2015 Plenário 
Trata-se de Agravo Regimental na Suspensão de Liminar interposto pelo Município de São Paulo e pelo Estado de São Paulo contra decisão que denegou Suspensão de Tutela Provisória - STP 815/SP. O julgamento se deu pelo Plenário do Supremo, em 7 de maio de 2015, por unanimidade e nos termos do voto do Relator Ministro Ricardo Lewandowiski, negaram provimento.

O peticionante é portador de Hepatite C e solicita utilização combinada dos medicamentos: i) Sofosbuvir $400 \mathrm{mg}$, cujo preço ao consumidor sem incidência de IMCS é de $\mathrm{R}$ \$ 51.699,88 e o preço para compras públicas sem incidência de ICMS é de R \$ 41.277,18; ii) Simeprevir $150 \mathrm{mg}$, cujo preço ao consumidor sem incidência de IMCS é de R \$30.727,23 e preço para compras públicas sem incidência de ICMS é de R \$24.532,62; e iii) Ribavirina 250 $\mathrm{mg}$, cujo preço ao consumidor sem incidência de IMCS é de R \$ 81,35 e o preço para compras públicas sem incidência de ICMS de R \$64,95. O custo do tratamento mensal R \$ 69.252,91 e o custo total do tratamento (12 semanas) é de $\mathrm{R} \$ 207.758,73$, calculado de acordo com o preço de venda ao governo (compras públicas).

A Portaria $\mathrm{n}^{\circ}$ 29, de 22 de junho de 2015 tornou pública a decisão de incorporar os medicamentos Sofosbuvir, Daclatasvir e Simeprevir para o tratamento da hepatite viral C crônica, conforme sítio na internethttp://conitec.gov.br/images/Relatorios/Portaria/2015/Portar iaSCTIE_29_2015.pdf, acessado em 17/06/2019.

A decisão do STF de manter a decisão a quo favorável ao peticionante se deu pouco mais de 1 mês antes de sua incorporação pelo SUS.

5. ARE 889216 / DF - Recurso Extraordinário com Agravo, Relator(a): Min. Dias Toffoli, Julgamento: 25/05/2015

Trata-se de um Recurso Extraordinário com Agravo interposto pela União. Em decisão monocrática, o Ministro Dias Toffoli, em 25 de maio de 2015, deu provimento ao Agravo, mas negou seguimento quanto à questão da legitimidade passiva.

O recorrente desejava reverter a decisão proferida pelo TRF da $1^{\mathrm{a}}$ região que não admitiu recurso extraordinário interposto contra acórdão de apelação que deferiu o fornecimento de medicamento de alto custo.

O peticionante é portador de Doença de Fabry e solicita o medicamento Replagal 1 $\mathrm{mg} / \mathrm{ml}$ (alfagalsidase), cujo preço ao consumidor sem incidência de IMCS é de R \$ 4.787,38 e o preço para compras públicas sem incidência de ICMS é de R $\$ 3.822,24$, sendo o custo do 
tratamento mensal de $\mathrm{R} \$ 3.822,24$, e seu custo anual de $\mathrm{R} \$ 45.866,88$, calculado de acordo com o preço de venda ao governo (compras públicas).

A Portaria $\mathrm{n}^{\mathrm{o}}$ 76, de 14 de dezembro de 2018 tornou pública a decisão de não incorporar a alfaagalsidase e beta-agalsidase como terapia de reposição enzimática na doença de Fabry, conforme sítio na internet http://conitec.gov.br/images/Relatorios/Portaria/2018 /PortariasSCTIE_75a81_2018.pdf, acessado em 17/06/2019.

A decisão do STF de manter a decisão a quo favorável ao peticionante se deu quase 3 anos antes da decisão de não incorporação pelo SUS.

6. ARE 881471 / AL - Recurso Extraordinário com Agravo, Relator(a): Min. Dias Toffoli, Julgamento: 09/06/2015

Trata-se de um Recurso Extraordinário com Agravo interposto pelo Município de Maceió. Em decisão monocrática do Ministro Dias Toffoli, em 9 de junho de 2015, negou-se seguimento ao recurso extraordinário.

O recorrente desejava reverter a decisão proferida pela Turma Recursal da Seção Judiciária de Alagoas, que não admitiu recurso extraordinário interposto contra acórdão de apelação que deferiu o fornecimento de medicamento de alto custo.

A peticionante é portadora de câncer de mama e solicita o medicamento Femara 2,5 mg (letrozol), cujo preço ao consumidor sem incidência de IMCS não estava disponível na listagem e preço para compras públicas sem incidência de ICMS é de $\mathrm{R} \$ 525,47$. O custo do tratamento mensal de $\mathrm{R} \$ 525,47$ e o custo anual de $\mathrm{R} \$ 6.305,64$, calculado de acordo com o preço de venda ao governo (compras públicas).

A Portaria $\mathrm{n}^{\circ}$ 22, de 10 de junho de 2014 tornou pública a decisão de incorporar a hormonioterapia prévia (pré-operatório, neoadjuvante) do câncer de mama, que inclui o medicamento em questão, conforme sítio da internet http://conitec.gov.br/images/Incorporados /Hormonioterapia-Cmama-FINAL.pdf, acessado em 17/06/2019.

A decisão do STF de manter a decisão a quo favorável ao peticionante se deu um ano depois da decisão de incorporação do medicamento pelo SUS.

7. SS 5192 MC / GO - Medida Cautelar na Suspensão de Segurança Relator(a): Min. Presidente Cármen Lúcia, Julgamento: 07/08/2017

Trata-se de Medida Cautelar na Suspensão de segurança ajuizada pelo Estado de Goiás, objetivando suspender os efeitos da medida liminar deferida pelo Relator do Mandado de Segurança no Tribunal de Justiça do Goiás, que determinou o fornecimento à menor AVB 
do medicamento Spinraza (nusinersena). Medida Cautelar indeferida pela Presidente do STF, a Ministra Cármen Lúcia, em 07 de agosto de 2017.

O peticionante é portador de Atrofia Muscular Espinhal tipo I e solicita o medicamento Spinraza (nusinersena), cujo preço ao consumidor sem incidência de IMCS é de R \$309.869,60 e preço para compras públicas sem incidência de ICMS de $\mathrm{R} \$ 247.399,94$. O custo do tratamento mensal de $\mathrm{R} \$ 247.399,94$ e o custo anual de $\mathrm{R} \$ 2.968 .799$,28, calculado de acordo com o preço de venda ao governo (compras públicas).

A portaria $\mathrm{n}^{\circ} 24$, de 24 de abril de 2019 tornou pública a decisão de incorporar o nusinersena para atrofia muscular espinhal (AME) 5q tipo I, conforme sítio da internet http://conitec.gov.br/images/Relatorios/Portaria/2019/PortariaSCTIE-24.pdf, acessado em 17/06/2019.

A decisão do STF de manter a decisão a quo favorável ao peticionante se deu pouco mais de um ano antes de sua incorporação pelo SUS.

8. ARE 1057975 / BA - Recurso Extraordinário com Agravo, Relator(a): Min. Ricardo Lewandowski, Julgamento: 05/10/2017

Trata-se de Recurso Extraordinário com Agravo, interposto pela União. Em decisão monocrática do Ministro Ricardo Lewandowiski, em 05 de outubro de 2017, negou seguimento ao recurso extraordinário.

$\mathrm{O}$ recorrente desejava reverter a decisão proferida pelo TRF da $1^{\mathrm{a}}$ região, que não admitiu recurso extraordinário interposto contra acórdão de apelação que deferiu o fornecimento de medicamento de alto custo.

O Peticionante é portador de Diabetes tipo 1 e solicita insulina Novorapid 100U/ml (Asparte) - $2.000 \mathrm{U} / \mathrm{ml}$ ao mês,cujo preço ao consumidor sem incidência de IMCS é de R \$ 147,34 e preço para compras públicas sem incidência de ICMS é R \$117,64. O custo do tratamento mensal é de $\mathrm{R} \$ 2.352,80$ e o custo anual de $\mathrm{R} \$ 28.233,60$, calculado de acordo com o preço de venda ao governo (compras públicas).

A Portaria $\mathrm{n}^{\circ}$ 10, de 21 de fevereiro de 2017 tornou pública a decisão de incorporar insulina análoga de ação rápida para o tratamento da Diabetes Mellitus Tipo 1, incluindo a insulina Asparte, conforme sítio da internet http://conitec.gov.br/images/Relatorios/ Portaria/2017/PortariasSCTIE-09e10_2017.pdf, acessado em 17/06/2019.

A decisão do STF de manter a decisão a quo favorável ao peticionante se deu cerca de 8 meses após da decisão de incorporação do medicamento pelo SUS. 
9. SL 1141 / MS - Suspensão de Liminar, Relator(a): Min. Presidente Cármen Lúcia, Julgamento: 16/01/2018

Trata-se de pedido de suspensão de liminar em segurança ajuizada por Mato Grosso do Sul, objetivando suspenderem-se os efeitos da tutela antecipada deferida pelo juízo da Primeira Vara da Comarca de Aparecida do Taboado/MS na Ação n. 080167842.2017.8.12.0024 e mantida pelo Relator do Agravo de Instrumento n. 200200744.2017.8.12.0900 no Tribunal de Justiça de Mato Grosso do Sul, que determinou a Mato Grosso do Sul e ao Município de Aparecida do Taboado fornecerem ao menor TVB o medicamento Spinraza (nusinersena). Suspensão de Liminar indeferida pela Presidente do STF, a Ministra Cármen Lúcia, em 16 de janeiro de 2018.

A decisão do STF de manter a decisão a quo favorável ao peticionante se deu pouco mais de um ano antes de sua incorporação pelo SUS.

10. STP 24 MC / MG - Medida Cautelar na Suspensão de Tutela Provisória Relator(a): Min. Presidente Cármen Lúcia, Julgamento: 25/04/2018

Trata-se de pedido de Suspensão de Tutela Provisória, com pedido de liminar, ajuizada pelo Município de Montes Claros/MG, objetivando suspender os efeitos da tutela provisória deferida pelo Tribunal de Justiça de Minas Gerais, para fornecer o medicamento Spinraza a menor portador de Atrofia Muscular Espinhal AME. Pedido de liminar para suspensão de tutela indeferido pela Presidente do STF, a Ministra Cármen Lúcia, em 25 de abril de 2018.

A decisão do STF de manter a decisão a quo favorável ao peticionante se deu pouco mais de um ano antes de sua incorporação pelo SUS.

11. ARE 1121505 / RN - Recurso Extraordinário com Agravo, Relator(a): Min. Ricardo Lewandowski, Julgamento: 25/04/2018

Trata-se de um Recurso Extraordinário com Agravo interposto pela União. Em julgamento monocrático do Ministro Ricardo Lewandowiski, em 25 de abril de 2018, negou-se seguimento ao recurso extraordinário.

$\mathrm{O}$ recorrente desejava reverter a decisão proferida pelo TRF da $5^{\mathrm{a}}$ região, que não admitiu recurso extraordinário interposto contra acórdão de apelação que deferiu o fornecimento de medicamento de alto custo.

O peticionante é portador de Diabetes Mellitus tipo 1 e solicita Insulina (Glargina) Lantus. Como a dosagem e posologia não foram informadas na decisão e, nem tampouco, pesquisas no processo originário retornaram esta informação, informa-se somente o valor 
médio do medicamento em todas as suas apresentações, ou seja Lantus Solostar $100 \mathrm{U} / \mathrm{ml}$ - 3 ml, Lantus $100 \mathrm{U} / \mathrm{ml}$ - 3 ml, Lantus $100 \mathrm{U} / \mathrm{ml}$ - $10 \mathrm{ml}$ e Lantus $100 \mathrm{U} / \mathrm{ml}$ - 3ml + cânula aplicadora. O preço médio ao consumidor sem incidência de IMCS é de R \$114,62 e preço médio para compras públicas sem incidência de ICMS é de R \$91,50. Não foi possível calcular o custo do tratamento mensal, bem como o anual.

A portaria $\mathrm{n}^{\mathrm{o}}$ 19, de 27 de março de 2019 tornou pública a decisão de incorporar insulina análoga de ação prolongada para o tratamento de diabetes mellitus tipo I, http://conitec.gov.br/images/Relatorios/2019/Relatorio_Insulinas_Analogas_DM1.pdf, acesso em 17/06/2019.

A decisão do STF de manter a decisão a quo favorável ao peticionante se deu quase um ano antes de sua incorporação pelo SUS.

12. ARE 1121083 / RJ - Recurso Extraordinário com Agravo, Relator(a): Min. Edson Fachin, Julgamento: 30/04/2018

Trata-se de Recurso Extraordinário com Agravo interposto pelo Estado do Rio de Janeiro contra decisão que denegou seguimento ao recurso extraordinário. Em decisão monocrática do Ministro Edson Fachin, em 30 de abril de 2018, negou seguimento ao recurso extraordinário.

O recorrente desejava reverter a decisão proferida pelo Tribunal de Justiça do Rio de janeiro, que não admitiu recurso extraordinário interposto contra acórdão de apelação que deferiu o fornecimento de medicamento de alto custo.

O peticionante é portador de Lupus Eritematoso Sistêmico e solicita o medicamento Forteo (Teriparatida) $250 \mathrm{mcg} / \mathrm{ml}$, dose: $20 \mathrm{mcg}$ dia, ou $0,08 \mathrm{ml}$ dia por 18 meses, cujo preço ao consumidor sem incidência de IMCS é de R \$2.150,41 e preço para compras públicas sem incidência de ICMS é de $\mathrm{R} \$ 1.716,89$. O custo do tratamento mensal é de $\mathrm{R} \$ 1.716,89$ e o custo total do tratamento por 18 meses $\mathrm{R} \$ 30.904,02$, calculado de acordo com o preço de venda ao governo (compras públicas).

A decisão do STF de manter a decisão a quo favorável ao peticionante se deu sem, sequer, haver submissão de proposta de incorporação do medicamento à CONITEC.

13. STP 101 / ES - Suspensão de Tutela Provisória Relator(a): Min. Presidente Dias Toffoli, Julgamento: 03/04/2019

Trata-se de pedido de Suspensão de Tutela Provisória, com pedido de liminar, ajuizada pela União, objetivando suspender os efeitos da tutela provisória mantida pela $8^{\mathrm{a}}$ Turma 
Especializada do Tribunal Regional Federal da $2^{\mathrm{a}}$ Região e concedida em sentença pelo Juízo da $5^{\text {a }}$ Vara Federal da Seção Judiciária do Estado do Espírito Santo, nos autos da ação civil pública $n^{\circ}$ 0007010- 81.2013.4.02.5001, para fornecer análogos de insulina de longa duração a pacientes diabéticos de difícil controle. Pedido de Suspensão de Tutela deferido pelo Presidente do STF, o Ministro Dias Toffoli, em 3 de abril de 2019.

Como essa decisão trata de uma ação civil pública, o cálculo do impacto será informado conforme relatório de incorporação de insulinas análogas:

\begin{abstract}
Análise de impacto orçamentário: Foi considerada a dose diária definida estabelecida pela OMS para todas as tecnologias (40 UI). A difusão das tecnologias foi estimada por mês, por meio de função logarítmica, com difusão de 50\% ao final do horizonte temporal de cinco anos. Os preços foram obtidos no Sistema Integrado de Administração de Serviços Gerais (SIASG). Foram feitos dois cenários populacionais, sendo um a partir de dados epidemiológicos e outro com dados de dispensação pelo SUS e pelo programa "Aqui Tem Farmácia Popular". No primeiro cenário, o impacto orçamentário incremental em relação à insulina humana NPH varia entre $\mathrm{R} \$ 5,5$ bi (glargina Basaglar ${ }^{\circledR}$ ) e $\mathrm{R} \$ 18,8$ bi (degludeca). No segundo, a variação é entre $\mathrm{R} \$ 1,1$ bi (glargina Basaglar) e R $\$$ 3,7 bi (degludeca). Após sugestão do plenário da CONITEC, foi calculado cenário baseado em dados de um estado que atualmente forneça insulinas análogas de ação prolongada. Foram utilizados dados do estado do Paraná, extrapolados para os demais estados por meio da taxa de uso desses medicamentos na população e na difusão diferenciada das tecnologias em estados que atualmente fornecem ou não fornecem tais tecnologias. Neste cenário, o impacto orçamentário estimado para o horizonte temporal de cinco anos foi de, aproximadamente, $\mathrm{R} \$ 863 \mathrm{mi}$ para glargina com aplicador e R $\$ 2,0$ bi para detemir com aplicador (BRASIL; MINISTÉRIO DA SAÚDE; COMISSÃO NACIONAL DE INCORPORAÇÃO DE TECNOLOGIAS NO SUS, 2018).
\end{abstract}

Em atenção à determinação judicial o Ministério da Saúde instaurou processo administrativo visando à elaboração de Protocolo Clínico e Diretrizes Terapêuticas - PCDT que contemplasse a utilização das insulinas análogas de longa duração para fins de tratamento da Diabetes Mellitus tipo 1, em pacientes para os quais a doença é instável ou de difícil controle, entretanto, o procedimento resultou em novo Protocolo Clínico e Diretrizes Terapêuticas da Diabetes Mellitus tipo 1 (Portaria Conjunta n 8, de 15/03/2018, do Ministério da Saúde), em que foi mantida a conclusão segundo a qual:

Este PCDT não recomenda o uso de insulinas análogas de longa duração ao invés da insulina NPH para pacientes com DM 1 com o objetivo de atingir melhor controle glicêmico ou prevenção de hipoglicemias, visto que não há evidência qualificada de segurança ou efetividade que justifique sua recomendação mesmo em subgrupos específicos de pacientes com DM 1, conforme recomendação da Comissão Nacional de Incorporação de Tecnologias (50). (BRASIL et al., 2018). 
Entretanto, a incorporação de insulina análoga de ação prolongada para o tratamento de diabetes mellitus tipo I, no âmbito do Sistema Único de Saúde - SUS se deu com a portaria $\mathrm{n}^{\text {o }}$ 19, de 27 de março de 2019 http://conitec.gov.br/images/Relatorios/2019/Relato rio_Insulinas_Analogas_DM1.pdf, acesso em 17/06/2019.

A decisão do STF de reformar a decisão a quo favorável ao peticionante se deu sete dias após a incorporação do medicamento pelo SUS, ou seja, o Tribunal não adjudicou medicamento já incorporado.

\section{RESULTADO DAS DECISÕES DO STF ANALISADAS}

Para o STF, a integralidade do direito à saúde corresponde a todo e qualquer tratamento de saúde solicitado, independentemente de seu custo, desde que registrado na ANVISA (entendimento firmado recentemente, após o julgamento do mérito da repercussão geral no RE 657.718, em 22/05/2019, Relator Min. Marco Aurélio) e comprovada tal necessidade por meio de simples laudo médico.

Nota-se que o conceito de mínimo social/existencial não é utilizado ou levado em consideração pelo STF nas apreciações sobre pedidos de medicamento de alto custo. Nesse sentido Cunha Filho (2013) argumenta que o STF parece entender que haja um contexto de recursos ilimitados, sendo possível adjudicar, a todos os que pleiteiam, o mais extenso tratamento de saúde. Esse entendimento é oposto à teoria da justiça proposta por Rawls, pois o autor pressupõe um ambiente no qual haja escassez moderada de recursos, único cenário possível para a existência das circunstâncias objetivas de justiça, ou seja, de conflitos de interesses resolúveis.

Dessa maneira, John Rawls define o mínimo social/existencial como um patamar suficiente para que as pessoas tenham possibilidade de gozar dos mesmos direitos de liberdade e que deve ser estabelecido com base em critérios que reconheçam a escassez de recursos (atendimento ao princípio do não exagero da tributação). No caso dos tratamentos de saúde, depreende-se que Rawls preconizaria que o mínimo social em saúde fosse definido por técnicos capazes de estabelecer os parâmetros de custo-efetividade e eficácia, pois medicamentos que não atendem a tais critérios não fazem parte do mínimo social. 
Já em relação à reserva do possível o STF a qualifica como desculpa do poder executivo para não efetivação do direito à saúde ou que o alto custo dos medicamentos não é capaz de gerar lesão à ordem econômica e orçamentária.

Outro fundamento que se repete no Supremo Tribunal Federal é a supremacia da tutela do cidadão hipossuficiente, entendido como aquele indivíduo desprovido de recursos financeiros para custear seu próprio tratamento. No AgR RE 818.572 $\mathrm{CE}$, julgado em 02/09/2014, o acórdão da $1^{\text {a }}$ Turma, cuja relatoria foi do Ministro Dias Toffoli, entende, por unanimidade, que pessoas carentes são aquelas que conseguem comprovar a impossibilidade de custear com recursos próprios o tratamento necessitado.

A necessidade de comprovação de hipossuficiência, que se repete em outras duas decisões analisadas: ARE 881471 / AL - Relator(a): Min. Dias Toffoli Julgamento: 09/06/2015; e ARE 1057975 / Ba Relator(A): Min. Ricardo Lewandowski Julgamento: 05/10/2017, não é uma interpretação constitucional consonante com o princípio da universalidade, que dispensa qualquer apuração da hipossuficiência do cidadão para a obtenção de tratamentos médicos custeados pelo Estado. Conclui-se que para o STF a saúde pública deve ficar restrita a todos os hipossuficientes, em relação aos quais a universalidade seria válida.

No entanto, em se tratando de medicamentos de alto custo, a comprovação de hipossuficiência é bastante fácil, até mesmo, para aqueles que possuem alta renda e maior capacidade para acionar o Poder Judiciário ao nível do Tribunal de cúpula. Nesse sentido, Cunha Filho (2013, p. 194) faz o seguinte comentário acerca das decisões do STF no âmbito da saúde:

[...] adere-se a uma espécie de teoria da igualdade distorcida, na qual as pessoas que possuem recursos para ingressar com ações judiciais são mais beneficiadas do que aquelas que estão fora do alcance da atuação das instâncias judiciais.

Melhor seria que os ministros do STF analisassem a situação dos menos favorecidos de maneira não casuística, mas globalmente, ante a adjudicação de tratamentos de alto custo, considerando a igual distribuição do mínimo social, ou seja, daquele patamar mínimo capaz de possibilitar o igual gozo das liberdades.

Porém, o STF não discorre uma única linha sobre os possíveis prejuízos à distribuição do mínimo social em saúde, nem tampouco, sobre as consequências negativas aos menos favorecidos. A desconsideração ao mínimo social prejudica a garantia que o Estado deve dar à igualdade no gozo das liberdades fundamentais. 
Das 13 decisões analisadas, apenas a STP 101/ES, derivada de uma ação coletiva, teve suspensa a adjudicação de medicamento, que, por ironia, já havia sido incorporado às políticas do SUS sete dias antes do seu julgamento.

Apenas uma das decisões analisadas teve como pedido medicamento que não foi incorporado até o momento presente e outra com recomendação de não incorporação. Trata-se, respectivamente do ARE 1121083/RJ e da ARE 889216/DF. Todas as demais decisões tiveram incorporação anterior ou posterior ao julgamento.

O STF adjudicou medicamentos incorporados previamente à data do julgamento em apenas 3 casos (AgRg RE 818.572/CE, ARE 881471/AL e ARE 1057975/BA), no entanto, a incorporação prévia não foi ao menos citada, sendo que se depreende que não houve consulta à CONITEC sobre a incorporação dos medicamentos solicitados.

Porém, a maioria das adjudicações de medicamentos se deu anteriormente à incorporação pela CONITEC, ou seja, em 7 das 13 decisões analisadas, ou em aproximadamente $54 \%$ dos casos.

A adjudicação pelo STF de medicamentos não incorporados pela CONITEC, como visto anteriormente, coloca em risco a distribuição do mínimo social (tratamentos incorporados ao SUS), já que o Judiciário, incapaz de atender aos requisitos técnico-científicos que estipulam a eficácia e a custo-efetividade do tratamento solicitado, realoca o orçamento previsto pelo SUS em prejuízo dos menos favorecidos.

As decisões selecionadas nos últimos cinco anos não vêm inovando em suas motivações e fundamentos, sendo que algumas posições são absolutas e não apresentam qualquer alteração.

A única decisão que se diferenciou quanto aos seus fundamentos foi a já citada Suspensão de Tutela Provisória (STP 101/ES), na qual o Presidente do STF, o Ministro Dias Toffoli, em 3 de abril de 2019, deferiu a suspensão da tutela provisória em uma ação civil pública, única decisão contrária ao fornecimento de medicamentos liminarmente, ainda que a decisão de suspender a tutela provisória tenha se dado sete dias após a incorporação das insulinas análogas pela CONITEC.

O pedido de Suspensão de Tutela Provisória (STP 101/ES), com liminar, foi ajuizado pela União, que objetivava suspender os efeitos da tutela provisória mantida pela $8^{\mathrm{a}}$ Turma Especializada do Tribunal Regional Federal da $2^{\text {a }}$ Região e concedida em sentença pelo Juízo da $5^{\text {a }}$ Vara Federal da Seção Judiciária do Estado do Espírito Santo, nos autos da ação civil 
pública $\mathrm{n}^{\circ}$ 0007010-81.2013.4.02.5001, para fornecer análogos de insulina de longa duração a pacientes diabéticos de difícil controle.

O Magistrado da ação originária, em primeiro grau, julgou procedente a ação civil pública formulada pelo Ministério Público Federal e deferiu, em sede de tutela antecipada, o acesso aos análogos de insulina a portadores de diabetes mellitus tipo 1 instáveis, mandando o SUS implantar protocolo de incorporação do medicamento e viabilizar o custeio ou distribuição às secretarias estaduais de saúde.

Em sede de apelação no TRF da $2^{a}$ Região, obteve-se acórdão no sentido de confirmar a decisão recorrida, inclusive com a manutenção do alcance dos efeitos da decisão a todo território nacional, por se tratar de direito difuso.

A suspensão da tutela provisória, no entanto, parece ser incongruente com critérios de justiça, já que na ação civil pública, de natureza coletiva, a antecipação da tutela é muito mais justa do que a antecipação realizada no âmbito de uma ação individual, pois, abrange todos aqueles indivíduos que também necessitam do medicamento solicitado, inclusive aqueles que têm dificuldade de acesso à justiça, assegurando maior equidade, o que, apesar de ter sido considerado e louvado pelo Ministro Presidente, não foi suficiente para convencê-lo da necessidade da manutenção da antecipação de tutela, ao contrário de outros pedidos de suspensão em ações individuais que foram indeferidas, como na ARE 1121505/RN, na qual se adjudicou idêntico medicamento, a insulina análoga Glarina.

Em sua fundamentação, o Ministro afirma a potencialidade de impacto deste tipo de ação (coletiva) e a dificuldade de que, uma vez, fornecido determinado direito social, este seja suspenso, e dessa forma, vislumbra que seus impactos são mais perceptíveis e que é mais prudente que seus efeitos se deem após o trânsito em julgado, pois a decisão recorrida adentra o cerne da política pública.

Entretanto, a decisão da ação individual também adentra o "cerne da política pública", mas nisso não se vê problema, pois o impacto financeiro é desconsiderado, enquanto que na ação coletiva isso se torna um problema que deve ser evitado, dada a sua abrangência. Amaral (2001) tenta explicar esta incongruência:

Tomada individualmente, não há situação para a qual não haja recursos. Não há tratamento que suplante o orçamento da saúde ou, mais ainda, aos orçamentos da União, de cada um dos Estados, do Distrito Federal ou da grande maioria dos municípios. Assim, enfocando apenas o caso individual, vislumbrando apenas o custo de cinco mil reais por mês para um coquetel de 
remédios, ou de cento e setenta mil reais para um tratamento no exterior, não se vê a escassez de recurso (AMARAL, 2001, p. 146).

A decisão pela suspensão da tutela provisória acaba por aderir a quase todas as teses da defesa, inclusive idênticas àquelas expendidas nas ações individuais, cujo impacto financeiro também é relevante.

Outra questão que pôde ser notada, é que, nas ações individuais, o envolvimento do julgador com a vida de pessoa determinada, que, muitas vezes, é uma criança, com nome informado nos autos e cuja história de vida passa a ser conhecida, leva o julgamento a um nível de comprometimento pessoal maior do julgador. Nas ações coletivas as pessoas não são individualizadas, o risco iminente de vida não possui um titular claro. Isso parece interferir no julgamento, sendo que a impessoalidade de uma ação coletiva propicia o distanciamento necessário para o julgador.

Outro julgamento relevante e esclarecedor de como o STF decide, foi a Medida Cautelar na Suspensão de segurança ajuizada pelo Estado de Goiás (SS 5192 MC/GO) objetivando suspender os efeitos da medida liminar deferida pelo Tribunal de Justiça de Goiás, que determinou o fornecimento do medicamento Spinraza (nusinersena) a uma criança. $\mathrm{O}$ pedido de suspensão foi indeferido pela Presidente do STF, a Ministra Cármen Lúcia, em 07 de agosto de 2017.

Em suas fundamentações a Ministra Presidente ignorou os fatos trazidos pelo recorrente, que alegava, dentre outras coisas, o risco de lesão à ordem, à saúde e a economia públicas, causada pelo custo alarmante do medicamento, cujo tratamento seria de quase R\$ 3.000.0000,00 (três milhões de reais) por semestre, o que representaria prejuízos ao atendimento de um enorme contingente de pessoas que necessitam dos serviços do SUS, com prejuízo de todas as políticas públicas gestadas para o atendimento de milhares de pessoas, sendo que somente o tratamento da impetrante equivaleria a $17 \%$ do orçamento anual destinado ao SAMU que atende a todo o Estado, e mais de $30 \%$ de tudo o que é gasto com as Unidades de Pronto Atendimento em um ano e que atendem milhões de pessoas.

A Ministra Cármen Lúcia não fundamentou a ausência de lesão à ordem e à economia públicas, utilizando mera afirmação de sua ausência. Novamente, quando a questão envolve a vida humana individualizada, o STF não faz nenhum esforço no sentido de analisar efeitos deletérios que não sejam relativos ao dano inverso (risco de morte ou agravo). 
Em momento algum a decisão, sequer, analisa o impacto à saúde pública do Estado de Goiás devido ao deferimento da medida, conforme alegado pela Fazenda Pública. O orçamento público e seu atendimento aos menos favorecidos, também não é, sequer, mencionado. O absolutismo do direito á vida é constante nos julgamentos de pedidos de medicamento; porém, o Supremo desconsidera as outras tantas vidas que são postas em risco devido à sua atitude míope em relação às implicações globais.

Tudo se resume a uma justiça casuística e individualizada, ou seja, a partir do momento em que se passa a conhecer o nome do paciente que necessita da droga, alternativas não existem à manutenção, a qualquer custo, daquela vida, que foi particularizada, ainda que a adjudicação do tratamento não seja garantia de sobrevivência. O drama invisível dos menos favorecidos não é levado a sério. A retirada de recursos, já escassos, que poderiam atender a milhares de pessoas cuja única possibilidade de tratamento é pelo sistema público de saúde, é uma forma de injustiça que não é, sequer, abordada.

O medicamento solicitado, denominado Spinraza (nusinersena) para tratamento da Atrofia Muscular Espinhal (AME 5q) foi recentemente incorporado aos protocolos do SUS, em março de $2019^{11}$. Seu elevadíssimo custo não foi impeditivo para a adoção dessa política pública, pois ficou demonstrada, de acordo com critérios científicos, que a droga traz efeitos concretos na melhoria da qualidade de vida dos pacientes e há custo-efetividade positiva, o que se coaduna perfeitamente ao mínimo social.

Apesar do alto impacto financeiro trazido pela incorporação do medicamento, os critérios técnico-científicos utilizados são superiores àqueles utilizados na distribuição do medicamento pelo Poder Judiciário, que é incapaz de realizar um estudo minimamente científico. Isso, a despeito da possibilidade de utilização de peritos, o que não é usual nas decisões sobre distribuição de medicamentos, sendo que os parâmetros gravitam em torno do direito e da ética da preservação da vida e da saúde, e, ao menos nas decisões analisadas, não se faz uma análise da justiça da distribuição dos remédios de alto custo levando em conta a situação dos menos favorecidos.

11 [...] baseado na evidência científica disponível e no custo do tratamento, considera-se que o nusinersena apresenta resultados de eficácia e segurança plausíveis para o tratamento de indivíduos com AME 5q tipo I. Para as demais populações portadoras de AME 5q as evidências são mais incipientes (MINISTÉRIO DA SAÚDE, 2019, p. 9). 


\section{CONCLUSÃO}

De tudo, depreende-se que as decisões do STF analisadas se distanciam da justiça como equidade proposta por Rawls, pois, em vista da escassez de recursos, não privilegia o mínimo social e adjudica tratamentos que não tiveram sua custo-efetividade e eficiência/eficácia estudadas pelo SUS em seus procedimentos de incorporação de tecnologias, o que é bastante prejudicial aos menos favorecidos.

Desse modo, é possível observar que a maior parcela da população, que não possui capacidade financeira para arcar com seus tratamentos de saúde mais básicos, não é protegida pelo Estado, notando-se uma exclusão destes indivíduos, logo, torna-se perceptível que a justiça como equidade no pensamento de Rawls não é efetivada pelas decisões do STF, que deveria se abster de adjudicar medicamentos não incorporados ao SUS pela CONITEC.

Além disso, não se trata apenas de uma ausência de um tratamento justo no sentido rawlsiniano, mas também um desrespeito à Constituição Federal no que se refere ao princípio da igualdade, ao direito à saúde, ao princípio da dignidade humana, ao princípio da universalidade da saúde e ao princípio da integralidade. Dessa forma, com o não cumprimento da Constituição, pode-se notar um enfraquecimento do próprio Estado, já que seus cidadãos não podem confiar naquilo que é garantido e protegido constitucionalmente.

Por fim, é importante ressaltar que, mediante a análise das decisões selecionadas, pode-se notar que o Poder Judiciário não possui uma estratégia harmônica para enfrentar a discussão concernente ao direito à saúde, ao mínimo existencial e à reserva do possível, já que fornece resultados diversos quando se tratam de ações individuais comparadas com ações coletivas, já que nestas há um pouco mais de rigor na análise sobre questões de equidade. Não é viável observar a concretização da justiça quando existe a prestação de serviços terapêuticos para algumas pessoas e para outras não. Essa é uma questão que deve ser debatida para que se desenvolvam soluções às inconsistências apontadas neste artigo, garantindo a preservação do princípio constitucional à igualdade o qual é sustentáculo primordial do Estado Democrático de Direito. 


\section{REFERÊNCIAS}

ACCA, Thiago dos S.. Uma análise da doutrina brasileira dos direitos sociais: saúde, educação e moradia entre os anos de 1964 e 2006. 2009. Dissertação (Mestrado em Filosofia e Teoria Geral do Direito) - Faculdade de Direito, University of São Paulo, São Paulo, 2009. doi:10.11606/D.2.2009.tde-03052010-105409. Disponível em: <http://www.teses.usp.br/teses/disponiveis/2/2139/tde-03052010-105409/en.php> Acesso em: 10 jul. 2019.

AITH, Fernando. Perspectivas do direito sanitário no Brasil: as garantias jurídicas do direito à saúde e os desafios de sua efetivação. In: SANTOS, L. (Coord.). Direito da saúde no Brasil. Campinas: Saberes, 2010.

ALEXY, Robert. Teoria de los derechos fundamentales. 2. ed. Madrid: Centro de estudios politicos y constitucionales, 2007.

AMARAL, Gustavo. Direito, escassez \& escolha. Rio de Janeiro: Renovar, 2001.

BARCELLOS, Ana Paula de. Constitucionalização das políticas públicas em matéria de direitos fundamentais: o controle político-social e o controle jurídico no espaço democrático. In: SARLET, I. W.; TIMM, L. B. (Coords.). Direitos Fundamentais orçamento e "reserva do possível". 2. ed. Porto Alegre: Livraria do Advogado, 2013. p. 101-132.

BOTAZZO, Carlos. Democracia, participação popular e programas comunitários. In: FLEURY, S.; AMARANTE, P.; BAHIA, L. (Coords.). Saúde em debate: fundamentos da reforma sanitária. Rio de Janeiro: Cebes, 2008.

BRASIL et al. Portaria Conjunta $n^{0} 8$, de 15 de março de 2018. Disponível em: http://www.in.gov.br/materia/-/asset_publisher/Kujrw0TZC2Mb/content/id/6848876/do12018-03-16-portaria-conjunta-n-8-de-15-de-marco-de-2018-6848872 Acesso em: 11.jul.2019.

BRASIL; MINISTÉRIO DA SAÚDE; COMISSÃO NACIONAL DE INCORPORAÇÃO DE TECNOLOGIAS NO SUS - CONITEC. Insulinas análogas de ação prolongada para o tratamento de diabetes mellitus tipo I: Relatório de recomendação. 2018. Disponível em: <http://conitec.gov.br/images/Relatorios/2019/Relatorio_Insulinas_Analogas_DM1.pdf> Acesso em 16.jun.2019.

BRASIL; MINISTÉRIO DA SAÚDE; COMISSÃO NACIONAL DE INCORPORAÇÃO DE TECNOLOGIAS NO SUS - CONITEC. Nusinersena para Atrofia Muscular Espinhal 5q: Relatório de recomendação. 2019.Disponível em: <http://conitec.gov.br/images/Relatorios/2019/Relelatorio_Nusinersena_AME5q_2019.pdf> Acesso em 12:jul.2019.

BRITO-SILVA, K.; BEZERRA, A. F. B.; TANAKA, O. Y. Direito à saúde e integralidade: Uma discussão sobre os desafios e caminhos para sua efetivação. Interface: Communication, Health, Education, v. 16, n. 40, p. 249-259, 2012. Disponível em: $<$ https://interface.org.br/wp-content/uploads/2015/02/v-16-n-40-jan-mar-2012.pdf> Acesso em: 10.out.2018 
CANOTILHO, J. J. G. Estudos sobre direitos fundamentais. 2. ed. São Paulo: Revista dos Tribunais, 2008.

CASTRO, Ione Maria Domingues de. Direito à saúde no âmbito do SUS: um direito ao mínimo existencial garantido pelo judiciário?. 2012. Tese (Doutorado em Filosofia e Teoria Geral do Direito) - Faculdade de Direito, University of São Paulo, São Paulo, 2012. doi:10.11606/T.2.2012.tde-02102012-162450. Disponível em: <http://www.teses.usp.br/teses/disponiveis/2/2139/tde-02102012-162450/en.php> Acesso em: 10 jul.2019.

COHN, A. O SUS e o direito à saúde: universalização e focalização nas políticas de saúde. In: LIMA, N. T. (Ed.). Saúde e democracia: história e perspectivas do SUS. Rio de Janeiro: Fiocruz, 2005.

LEAL, R. G. A quem compete o dever de saúde no direito brasileiro? Esgotamento de um modelo institucional. Revista de Direito Sanitário, v. 9, n. 1, p. 50-69, 2008. Disponível em: < http://www.revistas.usp.br/rdisan/article/view/13101> Acesso em 15.jan.2019.

LIMA, F. R. DE S. Saúde e Supremo Tribunal Federal. Lisboa: Juruá, 2016.

LIMA FILHO, F. DAS C. Garantia constitucional dos direitos sociais e a sua concretização jurisdicional. Revista do TRT da 24ª Região, n. 11, p. 19-54, 2006.

LIMA, R. S. DE F. Direito à saúde e critérios de aplicação. In: SARLET, I. W.; TIMM, L. B. (Eds.). Direitos Fundamentais orçamento e "reserva do possível". 2. ed. Porto Alegre: Livraria do Advogado, 2013. p. 237-253.

LOPES, J. R. DE L. Os tribunais e os direitos sociais no Brasil (saúde e educação): um estudo de caso revisitado. In: LOPES, J. R. DE L. (Ed.). Direitos sociais: teoria e prática. São Paulo: Método, 2006.

LOPES, J. R. DE L. Em torno da "reserva do possível". In: SARLET, I. W.; TIMM, L. B. (Eds.). Direitos fundamentais: orçamento e "reserva do possível". Porto Alegre: Livraria do Advogado, 2013. p. 155-174.

MARTINS, U. L. A judicialização das políticas públicas e o direito subjetivo individual à saúde, à luz da Teoria da Justiça Distributiva de John Rawls. Revista Brasileira de Políticas Públicas, v. 5, n. 2, 2015. Disponível em: < https://www.publicacoesacademicas.uniceub.br/ RBPP/article/view/3020> Acesso em: 20.mar.2019.

PINHEIRO, R. Integrality in the population's health care programs. Ciência \& Saúde Coletiva, v. 12 , n. 2, p. 344, 2007. <http://www.scielo.br/scielo.php?pid=S1413$81232007000200010 \&$ script=sci_abstract $>$ Acesso em: 25.abr.2019.

RAWLS, J. O liberalismo político. São Paulo: WMF Martins Fontes, 2011.

RAWLS, J. Uma teoria da justiça. Traducao Jussara SIMÕES. São Paulo: Martins Fontes, 
2016.

SARLET, I. W.; FIGUEIREDO, M. F. Reserva do possível, mínimo existencial e direito à saúde. Direitos Fundamentais \& Justiça, n. 1, p. 171-213, 2007. Disponível em: < http://dfj.emnuvens.com.br/dfj/article/view/590> Acesso em 25.fev.2019.

SCAFF, F. F. Sentenças aditivas, direitos sociais e reserva do possível. In: SARLET, I. W.; TIMM, L. B. (Eds.). . Direitos fundamentais: orçamento e reserva do possível. Porto Alegre: Livraria do Advogado, 2013. p. 133-154.

SLAIBI, M. C. B. G. Direito fundamental à saúde: tutela de urgência. Revista forense, v. 373, n. mai./jun., p. 421-434, 2004.

THIBAU, T.; GAZZOLA. A possibilidade de tutela coletiva do direito humano e fundamental à saúde no Estado constitucional. Revista da Faculdade de Direito da UFMG, n. 65, p. 651669, jul.dez., 2014. Disponível em: https://revista.direito.ufmg.br/index.php/revista/article/view/1652> Acesso em 11.ago.2021.

TORRES, R. L. A cidadania multidimensional na era dos direitos. 2. ed. Rio de Janeiro: Renovar, 2001.

TORRES, R. L. A metamorfose dos direitos sociais em mínimo existencial. In: SARLET, I. W. (Ed.). . Direitos fundamentais sociais: estudos de direito constitucional, internacional e comparado. Rio de Janeiro: Renovar, 2003. p. 1-46.

WANG, D. W. L. Escassez de recursos, custo dos direitos, ea reserva do possível na jurisprudência do Supremo Tribunal Federal. In: SARLET, I. W.; TIMM, L. B. (Eds.). . Direitos Fundamentais, Orçamento e "Reserva do Possível". 2. ed. Porto Alegre: Livraria do Advogado, 2013.

WEICHERT, M. A. O Direito à Saúde e o Princípio da Integralidade. In: SANTOS, L; SOUZA, A. (Eds.). . Direito da Saúde no Brasil. Campinas: Saberes, 2010.

Trabalho recebido em 23 de setembro de 2020

Aceito em 28 de agosto de 2021 